\title{
Study of the Corrosion Inhibitor of Steel in the Medium Acid in Different Concentrations of Imidazole
}

\author{
Lazhar Bechki*, Lounes A, Chouirfat K, Bechki MK and Kadri M \\ Univ Ouargla/Laboratory of Valuation and Promotion for Saharan Resources, Ouargla University, Ghardaia route 511. BP, Algeria
}

\begin{abstract}
Imidazole is a heterocyclic compound a five-membered of diunsaturated cyclic the structure composed of atoms three carbon and two atoms nitrogen in non-adjacent positions. The simplest member of the family is imidazole itself, colorless to pale yellow crystalline solid yellow with a faint odor amine like, soluble in water and alcohol, melts at $89^{\circ} \mathrm{C}$ to $256^{\circ} \mathrm{C}$. After Imidazole's are poorly soluble in water in general, but are dissolved in organic solvents such as chloroform, propylene glycol and polyethoxylated castor oil. Imidazole's have antibacterial, antifungal, antiprotozoal, and anthelmintic. Several distinct phenylimidazoles are therapeutically useful as antifungal agents against superficial infections or systemic be. Thiabendazoles that deworming and anti-fungal properties are compounds of the imidazole class. Benzimidazole is a bicyclic compound having an imidazole ring fused to the benzene. The Benzimidazole structure is a part of the portion of the nucleotide vitamin B12 and the core in some drugs, such as inhibitors of the proton pump and anthelmintic agents. Imidazole has two nitrogen atoms. One is slightly acidic, while the other is at the bottom. The imidazole and its derivatives are widely used as intermediates in the synthesis of biological target or pharmaceutical compounds, agrochemicals, dyes, photographic chemicals, corrosion inhibitors, curing agents for epoxy resin adhesives and plastic modifiers.
\end{abstract}

Keywords: Corrosion; Steel XC70; Inhibition; Adsorption isotherms

\section{Introduction}

The Corrosion, from the Latin 'corrodère' means biting, attacking. This is an unintended destruction of metals under the action of corrosive media (atmospheric or chemical reagents) [1,2]. After attack, metals tend to return to their original state of oxide, sulfide, carbonate, etc. more stable compared to the medium considered and thus suffer deterioration in their properties. Service metal materials are often in contact with a liquid or gaseous aggressive environment, so the corrosion phenomenon is a surface problem or more specifically the interface between a metal and a liquid or gaseous aggressive environment; as it was already mentioned above the process of corrosion leads to deterioration of metallic materials. This phenomenon taken today of considerable importance, since the use of most metals and alloys in modern life. Economically corrosion is of paramount importance. It is estimated that every year, for example, a quarter of steel production is destroyed by corrosion, which corresponds to about 150 million tons/ year or 5 tons/second. These losses could be higher if there was no protection against corrosion [3]. Replacement of corroded equipment and materials for the industry is very high financial burden which must be added the shortfall and corresponding to stopping the facilities to carry out repairs. Annual costs due to corrosion and its consequences amount to several billion dollars a year in most industrialized countries. In the US, the losses caused by corrosion are valued at more than $\$ 7$ billion [3-5]. Our research project which we have chosen is to fix a new inhibitor heterocyclic base, in order to combine their inhibitory property $[5,6]$.

\section{Results and Discussion}

We studied the influence of the concentration of the sulferique acid on the corrosion of the metal XC70; it was tested for the following concentrations: $0 \mathrm{M}$ to $50 \mathrm{ppm}$. The rate of corrosion is determined after $20 \mathrm{~min}$ of immersion, to an ambient temperature. Based on results we have shown that the corrosion rate increases when the concentration of $\mathrm{H}_{2} \mathrm{SO}_{4} \mathrm{l}$ acid $0.5 \mathrm{M}$ increases. Susceptibility to corrosion material is a function of the number of protons in the electrolyte. High proton concentration in the solution increases the aggressiveness of the environment. Among the factors that affect the rate of corrosion of steel, we include the factor of the immersion time, so for this we tested different immersion time of the steel that is 05 min to $50 \mathrm{~min}_{2} \mathrm{SO}_{4}$ medium $0.5 \mathrm{M}$. Analysis of the results in Table 1 and Figure 1 clearly shows that the steel corrosion rate in $\mathrm{H}_{2} \mathrm{SO}_{4} 0.5$ $\mathrm{M}$ decreases with the increase of immersion time. This decrease is due to the spontaneous formation of the protective layer adsorbed to the metal surface decreases the dissolution of the latter. The effect of the inhibitor Imidazole on corrosion of steel in acidic medium. For this we studied the influence of concentration on the corrosion of steel.

The experimental conditions used are:

1. Concentration of $\mathrm{H}_{2} \mathrm{SO}_{4}$ acid $0.5 \mathrm{M}$.

2. The temperature is of the ambient temperature solution.

The test compound concentration range is between $0 \mathrm{ppm}$ and 50 ppm.

\begin{tabular}{|c|c|c|c|c|}
\hline $\mathbf{n}^{\mathbf{b r}}$ & $\mathbf{t} \mathbf{( \mathbf { m i n } )}$ & $\mathbf{V}\left(\mathbf{K M n O}_{\mathbf{4}}\right) \mathbf{\Delta} \mathbf{m} \mathbf{( g )}$ & $\mathbf{m p} \mathbf{( g )}$ & $\mathbf{V g} /\left(\mathbf{g} / \mathbf{c m}^{2} . \mathbf{m i n}\right)$ \\
\hline 0 & 20 & 0.05 & 0.1116 & $3.080 \times 10^{-4}$ \\
\hline 1 & 40 & 0.10 & 0.2120 & $2.926 \times 10^{-4}$ \\
\hline 2 & 60 & 0.15 & 0.3013 & $2.772 \times 10^{-4}$ \\
\hline 3 & 80 & 0.20 & 0.3794 & $2.618 \times 10^{-4}$ \\
\hline 4 & 100 & 0.25 & 0.4464 & $2.464 \times 10^{-4}$ \\
\hline 5 & 120 & 0.29 & 0.4854 & $2.230 \times 10^{-4}$ \\
\hline 6 & 140 & 0.33 & 0.5155 & $2.032 \times 10^{-4}$ \\
\hline
\end{tabular}

Table 1: Final results of the speed of corrosion of iron XC70 in terms of time in an acid environment $\mathrm{H}_{2} \mathrm{SO}_{4}$ concentration $(0.5 \mathrm{~mol} / \mathrm{l})$ in the absence of the inhibitor.

*Corresponding author: Lazhar Bechki, Univ Ouargla/Laboratory of Valuation and Promotion for Saharan Resources, Ouargla University, Ghardaia route 511. BP, Algeria, Tel: 0774773768; E-mail: Ibechki1@gmail.com

Received November 25, 2015; Accepted November 26, 2015; Published November 30, 2015

Citation: Bechki L, Lounes A, Chouirfat K, Bechki MK, Kadri M (2015) Study of the Corrosion Inhibitor of Steel in the Medium Acid in Different Concentrations of Imidazole. J Environ Anal Chem 2: 167. doi:10.4172/2380-2391.1000167

Copyright: ( 2015 Bechki L, et al. This is an open-access article distributed under the terms of the Creative Commons Attribution License, which permits unrestricted use, distribution, and reproduction in any medium, provided the original author and source are credited. 
Citation: Bechki L, Lounes A, Chouirfat K, Bechki MK, Kadri M (2015) Study of the Corrosion Inhibitor of Steel in the Medium Acid in Different Concentrations of Imidazole. J Environ Anal Chem 2: 167. doi:10.4172/2380-2391.1000167

Page 2 of 5

The inhibitory effectiveness was determined after $20 \mathrm{~min}$ of immersion, at room temperature, Tables 2-5 and Figures 2-5, gives the values of the corrosion rate and the percentage of the inhibitory efficacy $\mathrm{R} \%$ calculated gravimetrically for different concentrations of $\mathrm{H}_{2} \mathrm{SO}_{4}$ medium inhibitor $0.5 \mathrm{M}$.

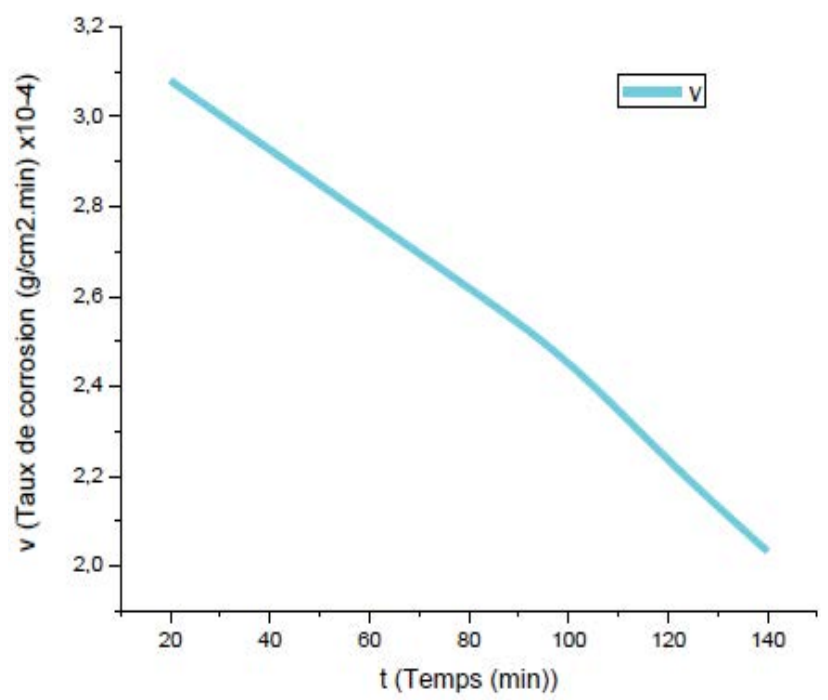

Figure 1: Change speed steels eat XC70 In terms of time in an acid environment $\mathrm{H}_{2} \mathrm{SO}_{4}$ concentration $(0.5 \mathrm{~mol} / \mathrm{l})$ in the absence of the inhibitor.

\begin{tabular}{|c|c|c|c|c|}
\hline $\mathbf{n}^{\mathbf{b r}}$ & $\mathbf{t} \mathbf{( m i n )}$ & $\mathbf{V}\left(\mathbf{K M n O}_{\mathbf{4}}\right)$ & $\mathbf{m p} \mathbf{( g )}$ & $\mathbf{V g} /\left(\mathbf{g} / \mathbf{c m}^{\mathbf{2}} \mathbf{. ~ m i n}\right)$ \\
\hline 0 & 20 & 0.035 & 0.0781 & $2.156 \times 10^{-4}$ \\
\hline 1 & 40 & 0.085 & 0.1802 & $2.487 \times 10^{-4}$ \\
\hline 2 & 60 & 0.12 & 0.2410 & $2.217 \times 10^{-4}$ \\
\hline 3 & 80 & 0.16 & 0.3035 & $2.094 \times 10^{-4}$ \\
\hline 4 & 100 & 0.20 & 0.3571 & $1.971 \times 10^{-4}$ \\
\hline 5 & 120 & 0.24 & 0.4017 & $1.848 \times 10^{-4}$ \\
\hline 6 & 140 & 0.28 & 0.4377 & $1.724 \times 10^{-4}$ \\
\hline
\end{tabular}

Table 2: Final results of the speed of corrosion of iron XC70 in terms of time in an acid environment $\mathrm{H}_{2} \mathrm{SO}_{4}$ concentration $(0.5 \mathrm{~mol} / \mathrm{l})$ in presence of inhibitory $10 \mathrm{ppm}$.

\begin{tabular}{|c|c|c|c|c|}
\hline $\mathbf{n}^{\mathbf{b r}}$ & $\mathbf{t} \mathbf{( \mathbf { m i n } )}$ & $\mathbf{V}\left(\mathbf{K M n O}_{\mathbf{4}}\right)$ & $\mathbf{m p} \mathbf{( g )}$ & $\mathbf{V g} /\left(\mathbf{g} / \mathbf{c m}^{\mathbf{2}} \mathbf{.} \mathbf{m i n}\right)$ \\
\hline 0 & 20 & 0.02 & 0.0446 & $1.232 \times 10^{-4}$ \\
\hline 1 & 40 & 0.065 & 0.1378 & $1.902 \times 10^{-4}$ \\
\hline 2 & 60 & 0.095 & 0.1908 & $1.755 \times 10^{-4}$ \\
\hline 3 & 80 & 0.13 & 0.2466 & $1.701 \times 10^{-4}$ \\
\hline 4 & 100 & 0.175 & 0.3035 & $1.675 \times 10^{-4}$ \\
\hline 5 & 120 & 0.215 & 0.3509 & $1.655 \times 10^{-4}$ \\
\hline 6 & 140 & 0.25 & 0.3906 & $1.540 \times 10^{-4}$ \\
\hline
\end{tabular}

Table 3: Final results of the speed of corrosion of iron XC70 in terms of time in an acid environment $\mathrm{H}_{2} \mathrm{SO}_{4}$ concentration $(0.5 \mathrm{~mol} / \mathrm{l})$ in presence of inhibitory $20 \mathrm{ppm}$.

\begin{tabular}{|c|c|c|c|c|}
\hline $\mathbf{n}^{\mathbf{b r}}$ & $\mathbf{t} \mathbf{( m i n})$ & $\mathbf{V}\left(\mathbf{K M n O}_{\mathbf{4}}\right)$ & $\mathbf{m p} \mathbf{( g )}$ & $\mathbf{V g} /\left(\mathbf{g} / \mathbf{c m}^{2} \cdot \mathbf{m i n}\right)$ \\
\hline 0 & 20 & 0.02 & 0.0334 & $1.232 \times 10^{-4}$ \\
\hline 1 & 40 & 0.045 & 0.1060 & $1.463 \times 10^{-4}$ \\
\hline 2 & 60 & 0.09 & 0.1807 & $1.47 \times 10^{-4}$ \\
\hline 3 & 80 & 0.12 & 0.2276 & $1.570 \times 10^{-4}$ \\
\hline 4 & 100 & 0.17 & 0.3035 & $1.675 \times 10^{-4}$ \\
\hline 5 & 120 & 0.21 & 0.3515 & $1.617 \times 10^{-4}$ \\
\hline 6 & 140 & 0.24 & 0.3906 & $1.478 \times 10^{-4}$ \\
\hline
\end{tabular}

Table 4: Final results of the speed of corrosion of iron XC70 in terms of time in an acid environment $\mathrm{H}_{2} \mathrm{SO}_{4}$ concentration $(0.5 \mathrm{~mol} / \mathrm{l})$ in presence of inhibitory $30 \mathrm{ppm}$.
From the results obtained in Tables 2-5 and Figures 2-5, we can make the following remarks:

\begin{tabular}{|c|c|c|c|c|}
\hline $\mathbf{n}^{\mathbf{b r}}$ & $\mathbf{t}(\mathbf{m i n})$ & $\mathbf{V}\left(\mathbf{K M n O}_{\mathbf{4}}\right)$ & $\mathbf{m p} \mathbf{( g )}$ & $\mathbf{V g} /\left(\mathbf{g} / \mathbf{c m}^{\mathbf{2}} \cdot \mathbf{m i n}\right)$ \\
\hline 0 & 20 & 0.015 & 0.0334 & $0.924 \times 10^{-4}$ \\
\hline 1 & 40 & 0.04 & 0.0848 & $1.170 \times 10^{-4}$ \\
\hline 2 & 60 & 0.08 & 0.1607 & $1.478 \times 10^{-4}$ \\
\hline 3 & 80 & 0.12 & 0.2276 & $1.570 \times 10^{-4}$ \\
\hline 4 & 100 & 0.16 & 0.2856 & $1.577 \times 10^{-4}$ \\
\hline 5 & 120 & 0.19 & 0.3180 & $1.463 \times 10^{-4}$ \\
\hline 6 & 140 & 0.23 & 0.3593 & $1.416 \times 10^{-4}$ \\
\hline
\end{tabular}

Table 5: Final results of the speed of corrosion of iron XC70 in terms of time in an acid environment $\mathrm{H}_{2} \mathrm{SO}_{4}$ concentration $(0.5 \mathrm{~mol} / \mathrm{l})$ in presence of inhibitory $40 \mathrm{ppm}$.

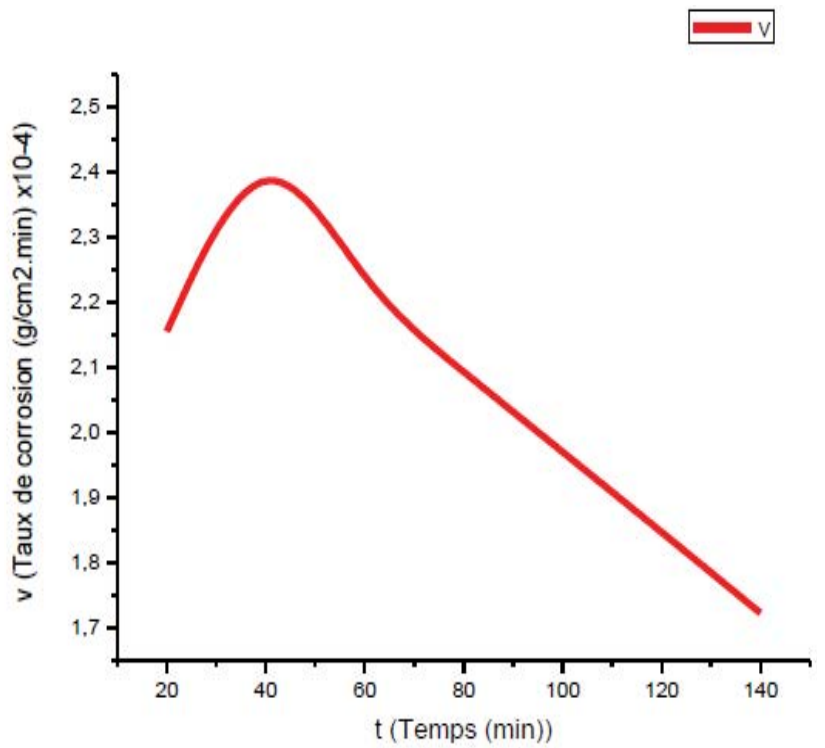

Figure 2: Change speed steels eat XC70 In terms of time in an acid environment $\mathrm{H}_{2} \mathrm{SO}_{4}$ concentration $(0.5 \mathrm{~mol} / \mathrm{l})$ in presence of inhibitory 10 ppm.

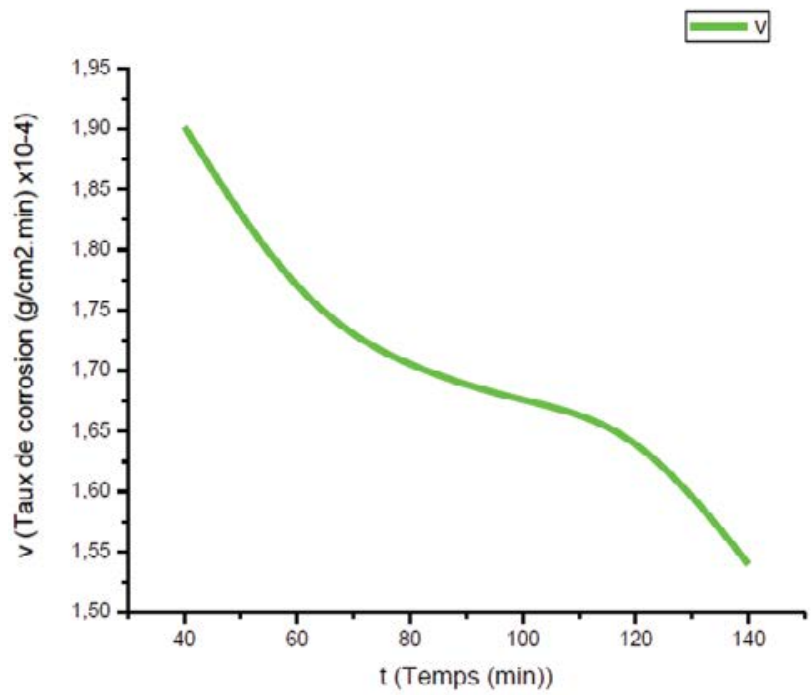

Figure 3: Change speed steels eat XC70 In terms of time in an acid environment $\mathrm{H}_{2} \mathrm{SO}_{4}$ concentration $(0.5 \mathrm{~mol} / \mathrm{l})$ in presence of inhibitory 20 ppm. 


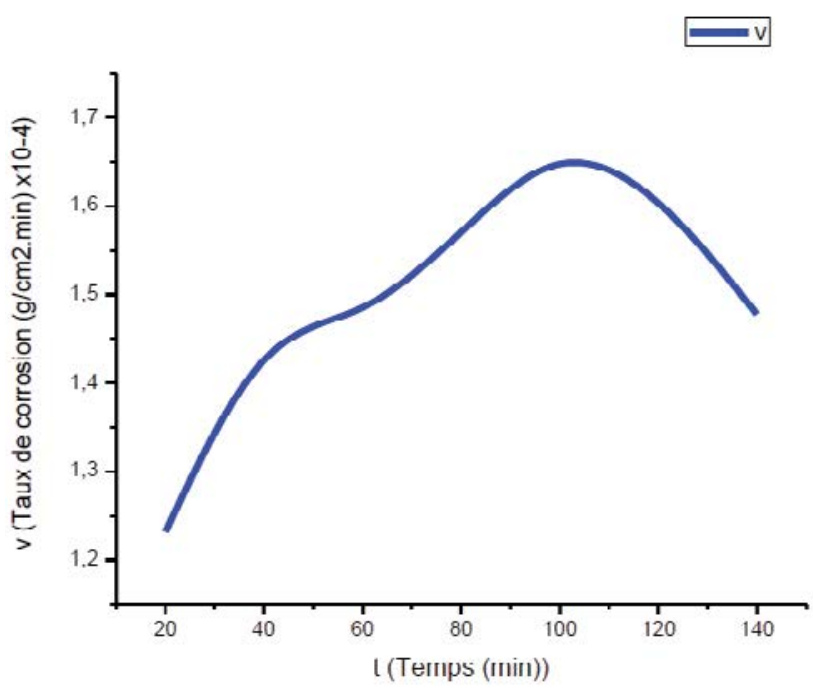

Figure 4: Change speed steels eat $\mathrm{XC70}$ In terms of time in an acid environment $\mathrm{H}_{2} \mathrm{SO}_{4}$ concentration $(0.5 \mathrm{~mol} / \mathrm{l})$ in presence of inhibitory $30 \mathrm{ppm}$.

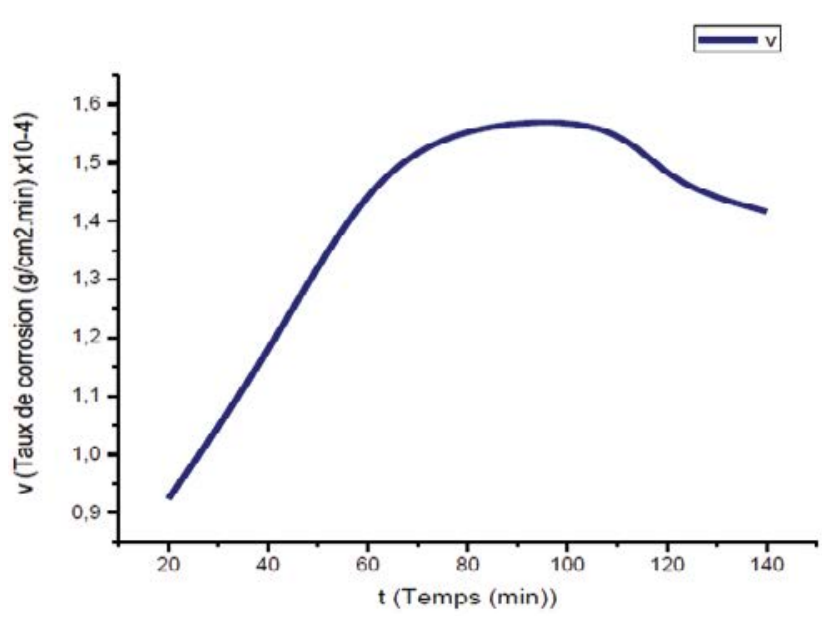

Figure 5: Change speed steels eat XC70 In terms of time in an acid environment $\mathrm{H}_{2} \mathrm{SO}_{4}$ concentration $(0.5 \mathrm{~mol} / \mathrm{l})$ in presence of inhibitory $40 \mathrm{ppm}$.

- The addition of this compound to the corrosive medium has an influence on the steel corrosion rate. This decrease in velocity is probably due to adsorption of the compound to the metal surface.

- The corrosion rate decreases as the inhibitory efficiency increases with the concentration of the inhibitor. This behavior could be attributed to the strong interaction of the inhibitor with the metal surface; it is clear from the adsorption of molecules on the metal surface.

- The adsorption of the compound on the metal surface can be attributed to nitrogen atoms, their electronic pair to the metal in the presence of the active site to the metal surface and make connections between them the inhibitory efficacy of this compound varies a compound to another, with a better inhibitory efficiency $(65.83 \%) 40$ ppm.

Through the results obtained during the study of inhibition imidazole in sulfuric acid $0.5 \mathrm{M}$ in the center of the steel XC70. We conclude the following:
Payoff inhibition is generally average in all concentration.

By the way stable (Polarization curves) note the following:

Of note there is a fluctuation in speed and corrosion current density and yield inhibition reaching greater value $65.83 \%$ at concentration $40 \mathrm{ppm}$. Through the results obtained to repel any best protection for steel XC70 In the acid environment of sulfuric acid $0.5 \mathrm{M}$ by inhibitor imidazole be at concentration $50 \mathrm{ppm}$.

\section{Experimental Part}

${ }^{1} \mathrm{H}$ NMR spectra and ${ }^{13} \mathrm{C}$ NMR were recorded on Bruker Avance DPX 200 spectrometers and AM300WB equipped with a QNP probe multi-cores. The chemical shift of the signals $(\delta)$ are expressed in ppm and signals correlated to $\mathrm{CDCl}_{3}(1 \mathrm{H}: 7.26 \mathrm{ppm}, 13 \mathrm{C}: 77.00$ ppm (the central peak)). The synthesized product spectrum was performed at room temperature $\left(\approx 22^{\circ} \mathrm{C}\right.$ air conditioned room), the product and analyzed in $\mathrm{CDCl}_{3} .1 \mathrm{H} \mathrm{NMR}$ characteristics are given as follows: $\delta(\mathrm{ppm})$ (m multiplicity, intensity I, coupling constant $\mathrm{J}(\mathrm{Hz})$, assignment) Tables 6-8 and Figures 6-10.

The progress of reactions was typically controlled by a thin layer chromatography. The plates used are of Merck Silica gel type 60 F254. The revelation of the plates is carried out by UV $(254 \mathrm{~nm})$ exposure to iodine, or an acid $\mathrm{KMnO}_{4}$ solution. The product was purified on silica gel column (SDS 60 - 0040-0063 mm, 230-400 mesh). Glassware is stored in an oven at $100^{\circ} \mathrm{C}$. Upon release, the Schlenk tubes were sealed and placed under vacuum with a ramp composed of a vacuum line and a line under argon. The vacuum ramps range from 0.01 to $0.05 \mathrm{~mm} \mathrm{Hg}$.

\section{Protocol}

Weight loss tests were performed by setting a sample on a polymer support queue in a beaker containing $40 \mathrm{ml}$ of the electrolyte. A water

\begin{tabular}{|c|c|c|c|c|}
\hline $\mathbf{n}^{\mathbf{b r}}$ & $\mathbf{t}(\mathbf{m i n})$ & $\mathbf{V}\left(\mathbf{K M n O}_{\mathbf{4}}\right)$ & $\mathbf{m p} \mathbf{( g )}$ & $\mathbf{V g} /\left(\mathbf{g} / \mathbf{c m}^{2} \cdot \mathbf{m i n}\right)$ \\
\hline 0 & 20 & 0.01 & 0.0223 & $0.616 \times 10^{-4}$ \\
\hline 1 & 40 & 0.03 & 0.0636 & $0.877 \times 10^{-4}$ \\
\hline 2 & 60 & 0.07 & 0.1406 & $1.293 \times 10^{-4}$ \\
\hline 3 & 80 & 0.11 & 0.2086 & $1.440 \times 10^{-4}$ \\
\hline 4 & 100 & 0.14 & 0.2499 & $1.379 \times 10^{-4}$ \\
\hline 5 & 120 & 0.17 & 0.2845 & $1.309 \times 10^{-4}$ \\
\hline 6 & 140 & 0.21 & 0.3281 & $1.293 \times 10^{-4}$ \\
\hline
\end{tabular}

Table 6: Final results of the speed of corrosion of iron XC70 in terms of time in an acid environment $\mathrm{H}_{2} \mathrm{SO}_{4}$ concentration $(0.5 \mathrm{~mol} / \mathrm{l})$ in presence of inhibitory $50 \mathrm{ppm}$.

\begin{tabular}{|c|c|c|c|c|c|c|c|}
\hline R\% & $\begin{array}{c}V \\
\text { (mm/An) }\end{array}$ & $\begin{array}{c}\text { RP } \\
\left(\text { Ohm.cm }{ }^{2}\right)\end{array}$ & $\mathrm{Bc}$ & $\mathrm{Ba}$ & $\begin{array}{c}\mathrm{i} \\
\left(\mathrm{mA} / \mathrm{cm}^{2}\right)\end{array}$ & $\underset{(\mathrm{mV})}{E}$ & $\begin{array}{l}\text { Cinh } \\
\text { (ppm) }\end{array}$ \\
\hline ------ & 16.39 & 13.58 & -121.4 & 106.8 & 1.4019 & -508.9 & $00 \mathrm{ppm}$ \\
\hline 65.01 & 5.737 & 25.94 & -81.9 & 01.2 & 0.4905 & -508.7 & 10 ppm \\
\hline 42.55 & 9.419 & 16.75 & -97.3 & 67.0 & 0.8053 & -490.5 & $20 \mathrm{ppm}$ \\
\hline 60.20 & 6.525 & 16.30 & -67.3 & 46.1 & 0.5579 & -469.8 & $30 \mathrm{ppm}$ \\
\hline 65.83 & 5.602 & 28.67 & -108.6 & 55.2 & 0.4790 & -479.2 & $40 \mathrm{ppm}$ \\
\hline 65.33 & 5.682 & 16.83 & -59.4 & 42.8 & 0.4859 & -474.0 & $50 \mathrm{ppm}$ \\
\hline
\end{tabular}

Table 7: Results curves Travel.

\begin{tabular}{|c|c|c|c|c|}
\hline $\mathbf{R} \%$ & $\mathbf{R t}\left(\mathbf{o h m . \mathbf { c m } ^ { 2 } )}\right.$ & $\mathbf{F} \mathbf{( H Z )}$ & $\mathbf{C}_{\text {dl }}\left(\boldsymbol{\mu} \mathbf{F} . \mathbf{c m}^{-2}\right)$ & $\mathbf{C}_{\text {inh }}$ (ppm) \\
\hline----- & 0.5871 & 0.31646 & 3.70923 & $00 \mathrm{ppm}$ \\
\hline 26.82 & 0.8023 & 0.25 & 6.41898 & $10 \mathrm{ppm}$ \\
\hline 64.43 & 1.6509 & 6.3291 & 5.21700 & $20 \mathrm{ppm}$ \\
\hline 29.28 & 0.8302 & 1.25 & 1.32838 & $30 \mathrm{ppm}$ \\
\hline 89.74 & 5.7265 & 0.79365 & 0.14431 & $40 \mathrm{ppm}$ \\
\hline 32.26 & 0.8668 & 1.2500 & 1.38701 & $50 \mathrm{ppm}$ \\
\hline
\end{tabular}

Table 8: Results Nquest in different concentrations. 


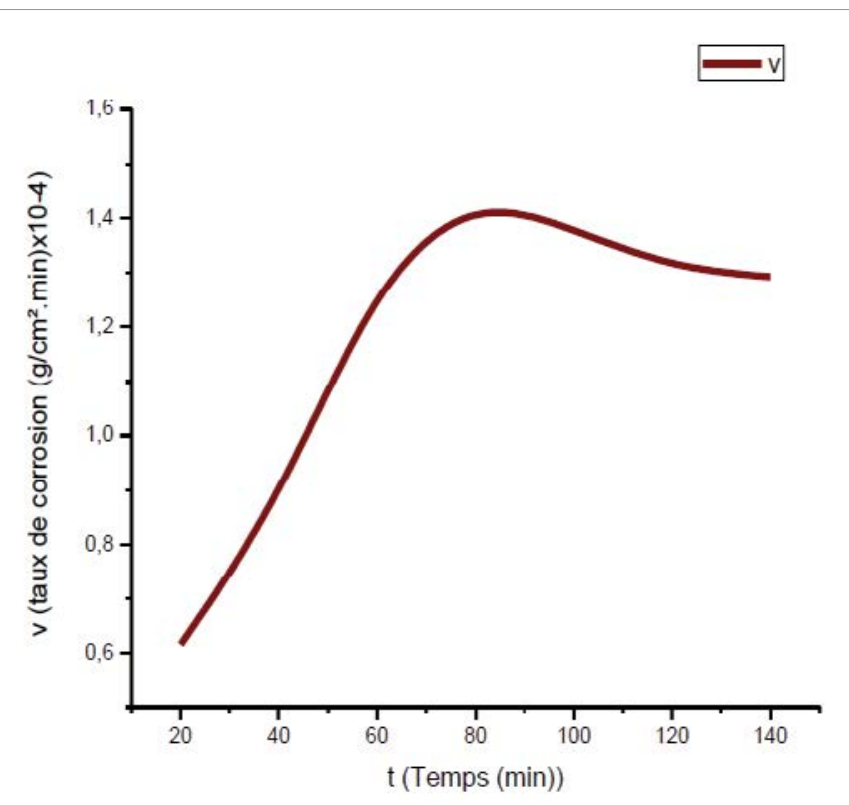

Figure 6: Change speed steels eat $\mathrm{XC70}$ In terms of time in an acid environment $\mathrm{H}_{2} \mathrm{SO}_{4}$ concentration $(0.5 \mathrm{~mol} / \mathrm{l})$ in presence of inhibitory $50 \mathrm{ppm}$.

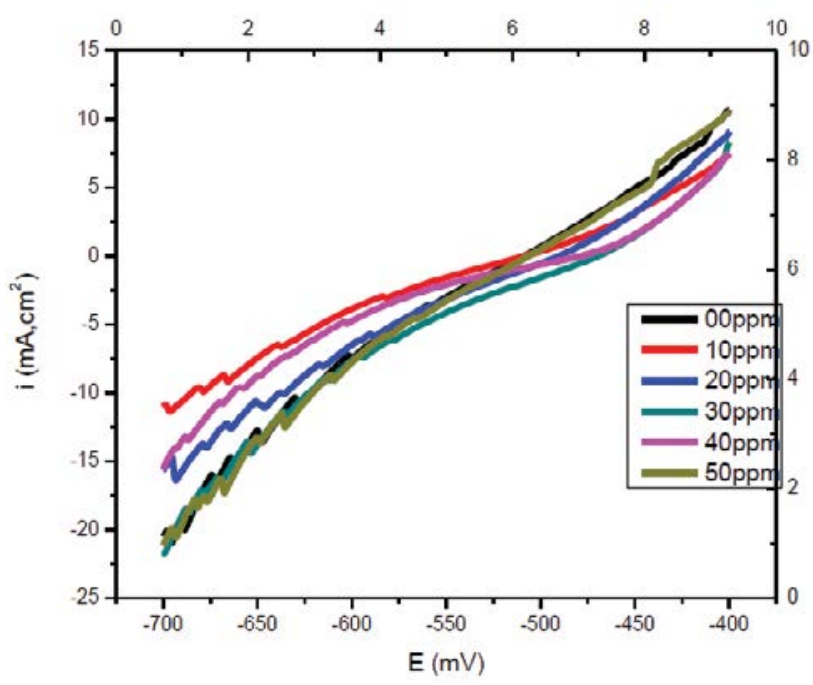

Figure 7: Polarization curves of different concentration.

bath was used to help maintain electrolyte at room temperature. The samples used are rectangular and have a total area of $18.49 \mathrm{~cm}^{2}$ (two+side faces). The samples are rinsed with distilled water and finally drying. The samples are weighed before and after each test and in the end there is a microscopic photograph of a surface of the workpiece before and after the soak.

\section{Conclusion}

In this work we have followed the inhibitory action of the imidazole used as inhibitor of corrosion of carbon steel XC70. I've touched on this work inhibitory effect of compound imidazole hat belongs to the nitrogenous compounds in the middle acid $\mathrm{H}_{2} \mathrm{SO}_{4} 0.5$ $\mathrm{M}$, corrosion of steel and rely on two ways the way classic and modern way electrochemical method.
The results were as follows:

- $\quad$ For classic way (volumetric titration method):

Compound with considerable effectiveness discourage based on the values of output inhibition, decreasing the speed of corrosion increased focus after reaching its highest value $44.24 \%$ for the concentration 50 ppm.

- Electrochemical method:

For stable way (polarization curves):

We note that the compound imidazole Inhibitor good corrosion of steel in the center of concentration sulfuric acid $0.5 \mathrm{M}$ a gave new values modern and decreased speed up corrosion inhibitor concentration and reached the maximum value of the payoff $65.83 \%$ at concentration 40 ppm.

We note that the compound behaves anodic and at other times sometimes cathodic behavior.

For changing the way (electrochemical impedance spectroscopy):

We note that the compound is effective inhibition of new, as there

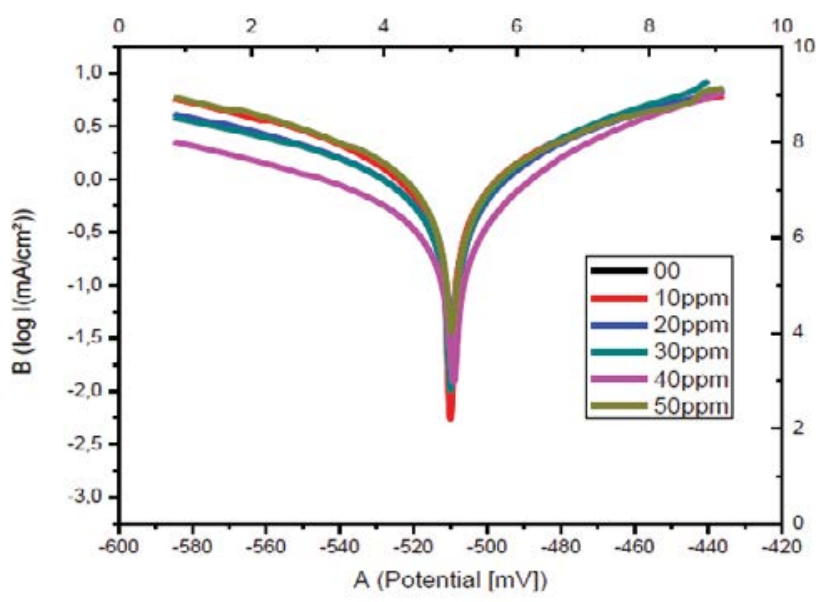

Figure 8: Draw curves Travel at different concentration.

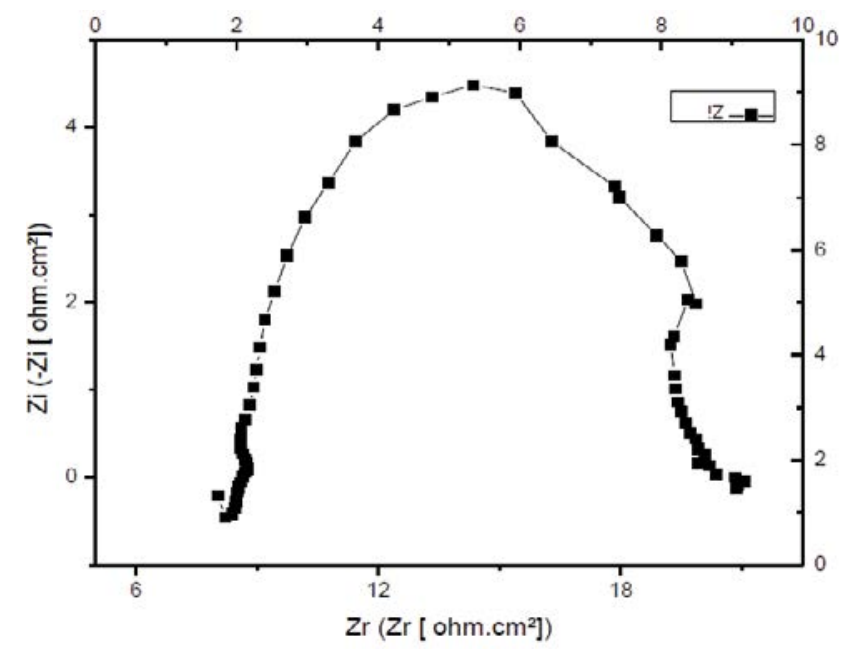

Figure 9: Draw a curved Nquest in the absence of inhibitor. 


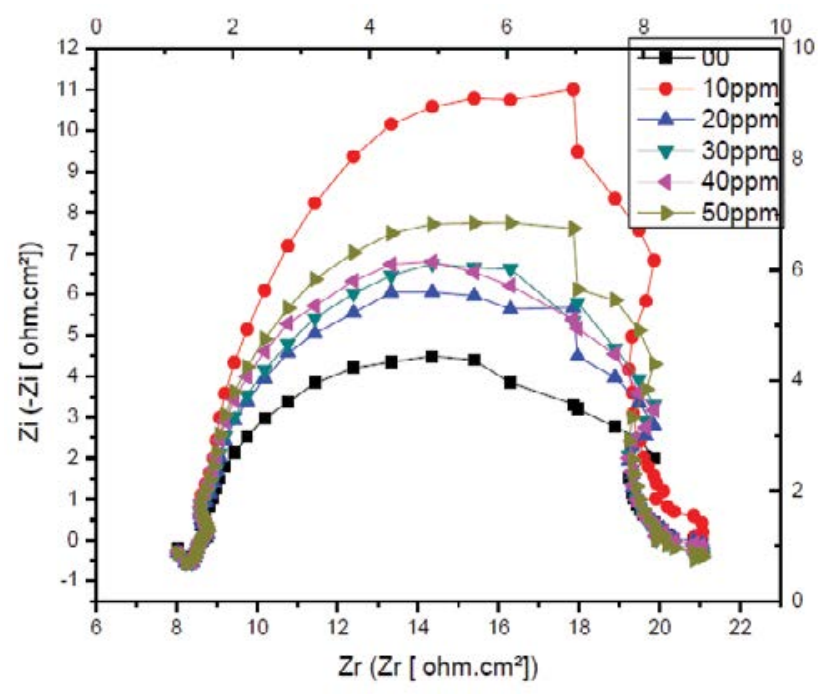

Figure 10: Draw curves Nquest in different concentrations.

are direct proportions between the focus and values $R_{t}$, and reverse between concentration and amplitude. As the value of $R_{t}, 5.7265$ (ohm. $\mathrm{cm}^{2}$ ) at concentration $40 \mathrm{ppm}$, which gives the best yield, which Worth
$89.74 \%$ the same goes for the values of capacitance are also good, with low values of the increased focus of the damper and at less worthless $0.14431\left(\mu \mathrm{F} . \mathrm{cm}^{-2}\right)$ at the same concentration.

\section{Acknowledgements}

We thank the Ministry of Research and the VPRS Laboratory of Ouargla University.

\section{References}

1. Oguzie EE (2008) Portugaliae Corrosion Inhibitive Effect and Adsorption Behaviour of Hibiscus Sabdariffa Extract on Mild Steel in Acidic Media Portugaliae. Electrochimica Acta 26: 303-314.

2. Sherif EM, Park SM (2006) Effects of 2-amino-5-ethylthio-1,3,4-thiadiazole on copper corrosion as a corrosion inhibitor in aerated acidic pickling solutions. Electrochimica Acta 51: 6556-6562.

3. Khaled KF, Abdel-Shafi NS (2013) Chemical and Electrochemical Investigations of L- Arginine as Corrosion Inhibitor for Steel in Hydrochloric Acid Solutions Int. J Electrochem Sci 8: 1409-1421

4. Shylesha BS, Venkatesha TV, Praveen BM (2011) Corrosion Inhibition Studies of Mild Steel by New Inhibitor in Different Corrosive Medium Research. Journal of Chemical Sciences 1: 46-50.

5. Chandrabhan VMA, Quraishi EE, Ebenso G (2013) Ultrasound Assisted Synthesis of $\mathrm{N}^{2}, \mathrm{~N}^{4}, \mathrm{~N}^{6}$-tris ((Pyridin-2-ylamino) methyl)-1, 3,5-triazine-2,4,6Triamine as Effective Corrosion Inhibitor for Mild Steel in $1 \mathrm{M}$ Hydrochloric Acid Medium Int. J Electrochem Sci 8: 10864-10877.

6. Bechki L (2015) Study of the Corrosion inhibitor for Steel XC70 in different Concentrations of acid and at room temperature of $\mathrm{N}$-mesitylimidazole. Int Res J Earth Sci 3: 7-12. 